\title{
Nano- and Micro- Carnauba Wax Emulsions versus Shellac Protective Coatings on Postharvest Citrus Quality
}

\author{
Marcela Miranda \\ São Paulo State University, School of Pharmaceutical Sciences, Araraquara, SP, 14800-901, Brazil
}

Xiuxiu Sun, Christopher Ference, Anne Plotto, Jinhe Bai, and David Wood

U.S. Horticultural Research Laboratory, U.S. Department of Agriculture, Agricultural Research

Service, 2001 South Rock Road, Fort Pierce, FL 34945

Odílio Benedito Garrido Assis and Marcos David Ferreira

Embrapa Instrumentação - Brazilian Agricultural Research Corporation, São Carlos, SP, 13560-970, Brazil

Elizabeth Baldwin

U.S. Horticultural Research Laboratory, U.S. Department of Agriculture, Agricultural Research

Service, 2001 South Rock Road, Fort Pierce, FL 34945

Additional INDEX words. Aroma volatiles, Citrus reticulata, Citrus sinensis, Copernica cerifera, fermentation, mandarin, tangor

\begin{abstract}
Coatings are generally applied to fruit as microemulsions, but nanoemulsions are still experimental. 'Nova' mandarins (Citrus reticulata) were coated with shellac or carnauba (Copernica cerifera) microemulsions or an experimental carnauba nanoemulsion; these were compared with an uncoated control during storage for 7 days at $20^{\circ} \mathrm{C}$. Coatings were also tested on 'Unique' tangors $\left(C\right.$. reticulata $\times C$. sinensis) stored for 14 days at $10^{\circ} \mathrm{C}$ followed by a simulated marketing period of 7 days at $20^{\circ} \mathrm{C}$. Fruit quality evaluations included weight loss, gloss, soluble solids (SS), titratable acidity (TA), pH, SS/TA ratio, internal $\mathrm{CO}_{2}, \mathrm{O}_{2}$, fruit juice ethanol, and other aroma volatile content. Sensory visual shine and tangerine $(C$. reticulata) flavor rank tests after storage were conducted, followed by an offflavor rating. The carnauba waxes resulted in less weight loss compared with the uncoated control and shellac coating during both experiments. There were no differences in gloss measurements of 'Nova' mandarins; however, shellaccoated fruit ranked highest for shine in a sensory test. For 'Unique' tangors, initially, shellac showed the highest gloss (shine) measurement; however, at the end of storage, the nanoemulsion exhibited the highest gloss, although it was not different from that of the microemulsion. Similarly, after storage, the nanoemulsion ranked highest for visual shine, although it was not different from that of the microemulsion. There were only minor differences in SS, TA, pH, and SS/TA among treatments. The internal $\mathrm{CO}_{2}$ gas concentration and juice ethanol content generally increased and internal $\mathrm{O}_{2}$ decreased during storage. The highest levels of $\mathrm{CO}_{2}$ and ethanol were found for the shellac treatment, as was the lowest $\mathrm{O}_{2}$, indicating anaerobic respiration. There were only minor differences among the other coating treatments; however, they were only sometimes different from those of the control, which generally had the highest $\mathrm{O}_{2}$, lowest $\mathrm{CO}_{2}$, and lowest ethanol. Shellac and the carnauba microemulsion also altered the volatile profile more than the control and the nanoemulsion did, especially for 'Unique' tangors. For 'Unique' tangors, the control and nanoemulsion ranked highest for tangerine flavor and had the least off-flavor at the end of storage. Among the coatings tested, the carnauba emulsions demonstrated less water loss, imparted more sustainable gloss, and caused less ethanol production than shellac, with the nanoemulsion exhibiting higher gloss measurements, less modifications of the atmosphere and volatile profile, and, consequently, better flavor compared with the microemulsion.
\end{abstract}

Received for publication 9 July 2020. Accepted for publication 13 Oct. 2020. Published online 17 November 2020.

We are thankful for the support provided by Coordenação de Aperfeiçoamento de Pessoal de Nível Superior-CAPES (PDSE/201688881.132643/2016-01), São Paulo Research Foundation (FAPESP; grant \# 2016/23419-5), Brazilian National Council for Scientific and Technological Development-CNPq (grant \# 407956/2016-6), and Empresa Brasileira de Pesquisa Agropecuária (EMBRAPA) from Brazil. We thank the U.S. Department of Agriculture. We also thank Milene C. Mitsuyuki for statistical advice and Holly Sisson and Elena Branca for laboratory assistance.

This paper was originally presented as an oral contribution at the $131^{\text {st }}(2018)$ meeting of the Florida State Horticultural Society.

Mention of a trademark or proprietary product is for identification only and does not imply a guarantee or warranty of the product by the U.S. Department of Agriculture. The U.S. Department of Agriculture prohibits discrimination in all its programs and activities on the basis of race, color, national origin, gender, religion, age, disability, political beliefs, sexual orientation, and marital or family status. E.B. is the corresponding author. E-mail: liz.baldwin@usda.gov.

This is an open access article distributed under the CC BY-NC-ND license (https://creativecommons.org/licenses/by-nc-nd/4.0/).
Tangerine/mandarin (Citrus reticulata), clementine (Citrus clementina), and satsuma (Citrus unshiu) world production in 2018-19 comprised 32.0 million tonnes of fresh fruit (U.S. Department of Agriculture, 2020). China is the largest producer of mandarins (22.0 million tonnes) and the second largest producer of fresh oranges (Citrus sp.) in the world, at 7.2 million tonnes. The largest sweet orange $(C$. sinensis) producer is Brazil, with a yield of 19.4 million tonnes (Food and Agricultural Organization of the United Nations, 2020). The development and application of protective coatings are recognized as alternative environmentally friendly approaches to reduce losses and improve postharvest conservation (Nayak et al., 2019).

Coatings provide a barrier between fruit and the external environment, induce a modified atmosphere within fruit (decreased $\mathrm{O}_{2}$ and increased $\mathrm{CO}_{2}$ ), and reduce water vapor diffusion, 
thus influencing respiration and transpiration rates, respectively. Coatings can influence the aroma volatile profile (Baldwin et al., 1995a, 1995b; El Hadi et al., 2013). For citrus (Rutaceae), the main criteria for coatings are the ability to impart shine, improve sales, and retard water loss to reduce shrinkage while maintaining fresh flavor (Hall, 2012). Resins and waxes are generally used (Bai and Plotto, 2012) because they are hydrophobic to varying degrees and impart shine.

Certain coating formulations can cause anaerobic respiration due to modification of the fruit internal atmosphere, causing fruit to produce high levels of ethanol and acetaldehyde, leading to off-flavor and trapping off-flavors within the fruit (Baldwin et al., 1999). In general, fruit produce a collection of volatile compounds that comprise their characteristic aroma, which is important for acceptability by consumers (El Hadi et al., 2013). Nisperos-Carriedo et al. (1991) reported that citrus, stored for $13 \mathrm{~d}$ at $21{ }^{\circ} \mathrm{C}$, showed an increase in some aroma volatiles, including alcohols, which were higher in commercial wax-coated oranges than in uncoated oranges, thus altering the aroma profile. This highlights the need to tailor functional and permeability proprieties of coatings to suit the unique requirements of every fruit and vegetable under specific storage regimes to achieve the best quality.

Coating fruit surfaces serves to replace the natural layer of wax removed by cleaning and handling processes in packing houses. Coatings generally used for citrus include microemulsions containing resins, waxes or blends of shellac, candelilla (Euphorbia cerifera) wax, carnauba (Copernica cerifera) wax, beeswax (Apis sp.), polyethylene, or petroleum waxes (Hall, 2012; Palou et al., 2015). Among commercial citrus coatings, shellac resin has been widely used alone or as a major component of "waxes" (Hagenmaier and Shaw, 1991) due to its ability to impart high shine (often measured as "gloss" by a gloss meter). Shellac does help to maintain moisture and reduce shrinkage, but not to the extent of true waxes. Carnauba wax has been largely used to form conventional microemulsion coatings, alone or mixed with other waxes and resins, to optimize shine (Bai and Plotto, 2012; De Freitas, et al., 2019; LuangtanaAnan and Limmatvapirat, 2019; Palou et al., 2015).

Wax emulsion coating properties, such as size and stability, are partly dependent on the size of the imbedded lipid micelle. Generally, the smaller the lipid micelle, the more clear, shiny, and stable the emulsion. Therefore, most fruit wax emulsions are microemulsions with microsized lipid micelles (typically $0.5 \mu \mathrm{m})$ (Hall, 2012). As technology has advanced, nanoemulsions (nano $=1-100 \mathrm{~nm}$ ) have been developed; however, there are few studies of carnauba nanostructure-based coatings compared with those of polysaccharide-based nanocoatings such as nanochitosan (González-Saucedo et al., 2019; Nguyen and Nguyen, 2020; Pilon et al., 2014). However, Miranda (2015) developed a carnauba wax nanoemulsion coating that exhibited small nano-sized $(\approx 44 \mathrm{~nm})$ lipid micelles, allowed gas exchange, reduced water loss, and imparted shine and stability. These coatings, however, may have different gas permeability properties compared with conventional microemulsions due to the change in structure.

In this context, edible coatings can contribute to fruit quality and shelf life by improving visual quality and reducing postharvest losses due to desiccation if the formulation does not cause off-flavor due to modification of the internal fruit atmosphere. During this study, a carnauba nanoemulsion coating was evaluated and compared with typical shellac and carnauba microemulsion coatings on two citrus species to determine if the nanoemulsion or microemulsion coating structure would impart more shine and affect coating permeability, thus affecting the fruit flavor.

\section{Materials and Methods}

Fruit. Approximately 200 'Nova' mandarins (C. reticulata) and 300 'Unique' tangors $(C$. reticulata $\times C$. sinensis) were used in two experiments. 'Unique', or 'Ortanique', is believed to be a spontaneous hybrid of a sweet orange and a mandarin that was first found in Jamaica (Nugent et al., 1967). Fruit were obtained from Al's Family Farms Citrus, Fort Pierce, FL. The fruit were selected for uniformity of size $(\approx 70$ and $80 \mathrm{~mm}$ in diameter for 'Nova' and 'Unique', respectively) and lack of defects, washed with commercial fruit cleaner (JBT 395; JBT FoodTech, Lakeland, FL), rinsed, and sanitized with 100 $\mathrm{mg} \cdot \mathrm{L}^{-1}$ peroxyacetic acid (PAA) (Jet-Oxide; Jet Harvest Solutions, Longwood, FL) for $3 \mathrm{~min}$ and then air-dried at room temperature.

CoAting preparations. A conventional carnauba wax microemulsion was formulated according to Hagenmaier and Baker (1997), with a slight modification. Carnauba wax emulsion was prepared in an open reactor by heating $45 \mathrm{~g}$ of carnauba wax type I (Strahl \& Pitsch, West Babylon, NY), 5 g oleic acid, $5 \mathrm{~g}$ myristic acid, $28 \mathrm{~g}$ ammonium hydroxide (all Sigma-Aldrich Chemical Co., St. Louis, MO), and deionized water $(175 \mathrm{~g})$ at $105^{\circ} \mathrm{C}$ with constant mechanical stirring (800 $\mathrm{rpm}$ ) for $3 \mathrm{~m}$. Then, under mechanical stirring, the emulsion was cooled to $50{ }^{\circ} \mathrm{C}$. The carnauba wax nano-emulsion was prepared with an oil phase composed of carnauba wax type 1 (150 g) and oleic acid (30 g) from Sigma-Aldrich Chemical Co. (St. Louis, MO). The water phase was composed of $20 \mathrm{~g}$ ammonium hydroxide, dimethylpolysiloxane $(0.1 \mathrm{~mL}$; SigmaAldrich Chemical Co.), and deionized water (775 g). Formulation of the nanoemulsion was accomplished by the inversion phase of the water in oil $(\mathrm{W} / \mathrm{O})$ to oil in water $(\mathrm{O} / \mathrm{W})$ system. The diameter size of the lipid micelles obtained was $44 \pm 8 \mathrm{~nm}$, with a narrow polydispersion index $(0.28)$ and zeta potential of $-43.8 \mathrm{mV}$ (Miranda, 2015) measured by a zeta potential analyzer (Zetasizer Nano ZS; Malvern Instruments, Westborough, MA). The microemulsion, in comparison, had a larger dispersion of droplet sizes and a higher polydispersion index $(\mathrm{PDI}=1.0)$ than the nanoemulsion $(\mathrm{PDI}=0.28)$.

Fruit PRocessing AND COATING. This research was performed during two experiments. The first experiment tested coatings on 189 'Nova' mandarin fruit with the following treatments: laboratory-made, simulated commercial carnauba wax microemulsion; a commercial shellac microemulsion (Stay Fresh 590HS, JBT FoodTech); an experimental carnauba nanoemulsion wax; and uncoated fruit. The commercial shellac microemulsion was included for a true commercial comparison of shellac resin. The second experiment was conducted with the same treatments but applied to 289 'Unique' tangor fruit. Fruit were coated by spreading $1 \mathrm{~mL}$ of coating per fruit by hand while wearing latex gloves. Coated fruit were then dried with a heat gun $\left(50^{\circ} \mathrm{C}\right)$ for $60 \mathrm{~s}$ before analyses and storage, simulating industry drying techniques.

During the first experiment, 'Nova' mandarins were stored for $7 \mathrm{~d}$ at $20^{\circ} \mathrm{C}$ and quality analyses were performed initially ( 0 d) and at the end of storage ( $7 \mathrm{~d})$. During the second experiment, 'Unique' fruit were stored at $10{ }^{\circ} \mathrm{C}$ for $14 \mathrm{~d}$, followed by a 
A

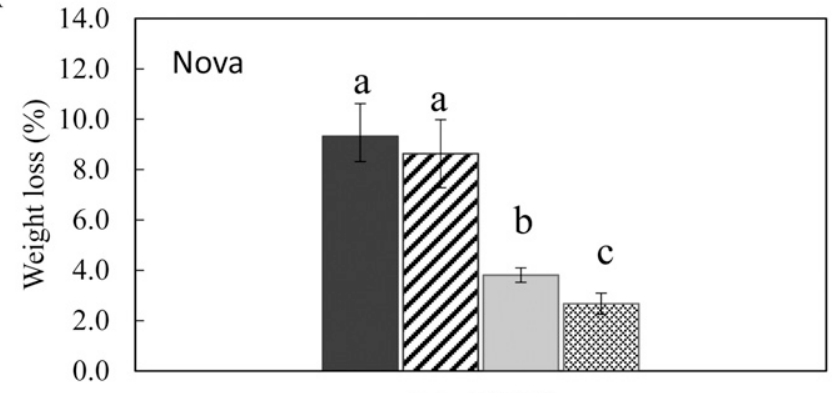

B

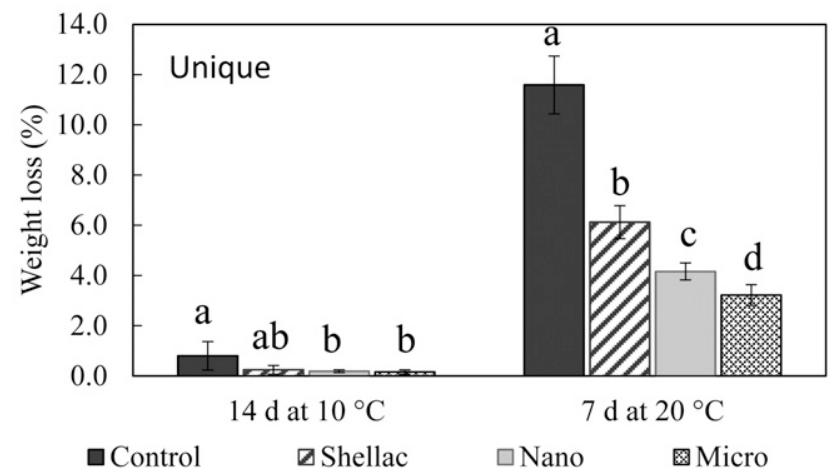

Fig. 1. Nanoemulsions and microemulsions of carnauba wax that help to slow water/weight loss from citrus fruit compared with a commercial shellac microemulsion. (A) Weight loss of coated and uncoated 'Nova' mandarins and (B) weight loss of 'Unique' tangors (10 fruit/treatment). For each storage period, columns with different letters are significantly different according to Duncan's test $(P<0.05)$

simulated marketing period of $7 \mathrm{~d}$ at $20{ }^{\circ} \mathrm{C}$, which is more typical for the industry. Quality analyses were performed initially $(0 \mathrm{~d})$, after $14 \mathrm{~d}$ of cold storage $\left(10^{\circ} \mathrm{C}\right)$, and again after the simulated marketing period $\left(7 \mathrm{~d}\right.$ at $\left.20^{\circ} \mathrm{C}\right)$. The relative humidity (RH) was $80 \%$ to $85 \%$ for all storage.

Fruit Quality. Fruit were gently hand-juiced using a food service juicer at room temperature to avoid peel oil in the juice (Baldwin et al., 2012). Juice aliquots $(3 \mathrm{~mL})$ were immediately pipetted in crimp-capped vials for gas chromatography (GC), frozen in liquid $\mathrm{N}_{2}$, and stored at $-80^{\circ} \mathrm{C}$ to optimize the volatile content. In addition, $40 \mathrm{~mL}$ of juice was pipetted into plastic tubes and stored at $-20{ }^{\circ} \mathrm{C}$ for sugar and acid analyses. The SS content of the juice was determined by the refractive index with a digital refractometer (PR-101; Atago, Tokyo, Japan). The TA and $\mathrm{pH}$ were calculated from titration of $10 \mathrm{~mL}$ of juice with 0.1 $\mathrm{mol} \cdot \mathrm{L}^{-1} \mathrm{NaOH}$ to the $\mathrm{pH} 8.1$ endpoint using an autotitrator (DL50; Mettler Toledo, Columbus, $\mathrm{OH}$ ) and expressed as the percent of juice. The ratio (SS/TA) was the proportion of sugar and acid (Baldwin et al., 2012). For SS, TA, pH, and SS/TA, 15 fruit were juiced per treatment (five composite replicates of three fruit each).

From this same juice, ethanol and other volatile compounds were quantified by GC (6890; Agilent Technologies, Santa Clara, CA) using a standard curve with authentic standards (Baldwin et al., 2012). Temperatures of the oven, injector, and detector were 70,250 , and $250{ }^{\circ} \mathrm{C}$, respectively. For quantification of ethanol and other aroma volatiles, $3 \mathrm{~mL}$ of fruit juice was transferred to a $10-\mathrm{mL}$ crimp-capped vial, rapidly frozen in liquid $\mathrm{N}_{2}$, and then stored at $-80^{\circ} \mathrm{C}$. Frozen samples were later thawed under running tap water and inserted in a Gerstel multipurpose auto sampler for head space injection $(3 \mathrm{~mL})$ in the gas chromatograph equipped with a polar column (Stabilwax; Restek Corp., Bellefonte, PA), a nonpolar low-bleed column (HP-5; Agilent Technologies) and a flame ionization detector. The gas flow rates for $\mathrm{He}, \mathrm{H}_{2}$, and air were 10, 35, and $350 \mathrm{~mL} \cdot \mathrm{min}^{-1}$, respectively. Temperatures of the oven, injector, and detector were 90,200 , and $250^{\circ} \mathrm{C}$, respectively. In addition to ethanol, common citrus volatiles were analyzed, including the alcohols hexanol, cis-3-hexenol, trans-2-hexenol, methanol, 2-methylpropanol, $\alpha$-terpineol, and linalool; aldehydes acetaldehyde, decanal, and hexanal; esters methybutanoate, ethylbutanoate, ethylacetate, ethylhexanoate, and ethyl-3hydroxyhexanoate; and terpenoids valencene, limonene, myrcene, $\alpha$-pinene, sabinene, and $\gamma$-terpinene. Volatile compound identification was confirmed using solid phase microextraction (SPME) $(50 / 30 \mu \mathrm{m}$ DVB/CAR/PDMS; Supelco, Bellefonte, PA) and GC-mass spectrometry (MS), as reported by Wang et al. (2015). The instrument and column for SPME injection were performed using GC-MS (6890 GC $+5973 \mathrm{~N}$ MS, Agilent Technologies) with a nonpolar column $(0.25 \mathrm{~mm} \times 60 \mathrm{~m}, 0.50$ $\mu \mathrm{m}$-thick film thickness, DB-5, Agilent Technologies).

Internal gases, $\mathrm{CO}_{2}$ and $\mathrm{O}_{2}$, from 10 fruit samples per treatment were evaluated by withdrawing a $10-\mathrm{mL}$ internal fruit gas sample from the fruit columella using a syringe while the fruit was submerged in room temperature water. These samples were analyzed using a gas chromatograph (Hewlett Packard 5890A, Agilent Technologies) fitted with a CTR column (Cole-Parmer, Vernon Hills, IL) and a thermal conductivity detector. The gas flow rates for helium and air were 80 and $350 \mathrm{~mL} \cdot \mathrm{m}^{-1}$, respectively. Temperatures of the oven, injector, and detector were 70,250 , and $250{ }^{\circ} \mathrm{C}$, respectively. Weight loss of 10 fruit per treatment was measured during storage, and results were expressed as a percentage of initial weight.

Gloss Measurements. A reflectometer (micro-TRI-gloss; BYK-Gardner, Colombia, MD) was used to evaluate gloss units, which are an indication of visual shine for coating formulations on test paper $(140 \times 254 \mathrm{~mm})$ and on the fruit. For test papers, an aliquot of $0.5 \mathrm{~mL}$ of each coating was spread on a $0.05-\mathrm{mm}$-thick polished paper (Leneta Co., Mahwah, NJ) with a $0.1-\mathrm{mm}$ castor (BYK-Gardner) with a speed of $1 \mathrm{~cm} \cdot \mathrm{s}^{-1}$. The control consisted of uncoated paper. Five papers per treatment were used, and measurements were repeated five times per paper at different positions. The reflectance was measured at angles of $20^{\circ}$ for test papers (Bai et al., 2003a) and $60^{\circ}$ for fruit (Bai et al., 2003b) according to the manufacturer's instructions because the paper is flat and the fruit is round. For coated fruit, a case with a circular 19-mm-diameter orifice was attached to the equipment to accommodate the round fruit shape. For gloss measurements, 10 fruit per treatment were used and measurements were performed twice at opposite points of the equatorial region of the fruit.

SENSORY VISUAL SHINE ANALYSES. Coated fruit were visually evaluated for shine by 25 and 19 panelists for 'Nova' and 'Unique' fruit, respectively, for comparison with the gloss units measured with the reflectometer. Panelists consisted of laboratory staff familiar with the assessment of citrus products. For 'Nova', two groups of four fruit were presented, with each group containing all four treatments, and panelists were asked to pair fruit by appearance (tetrad test) (Ennis, 2012). Then, panelists were asked to rank the pairs for shine in decreasing order of shine intensity (most shine to least shine). For 'Unique' 
A

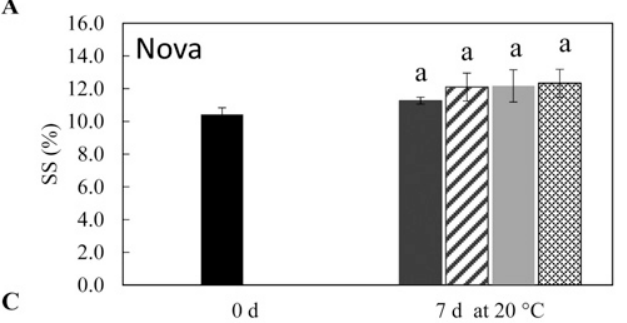

C

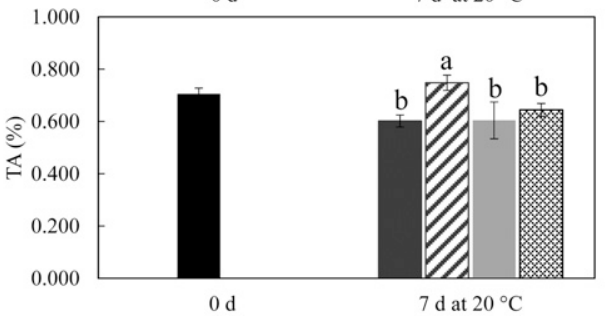

E

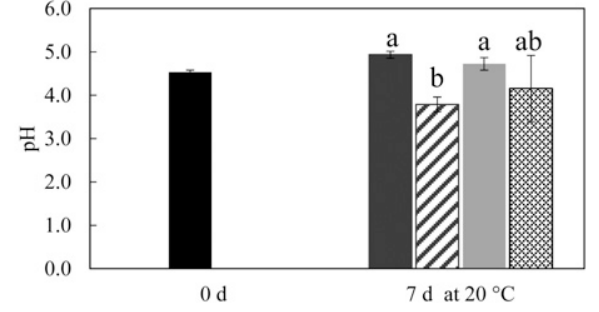

G

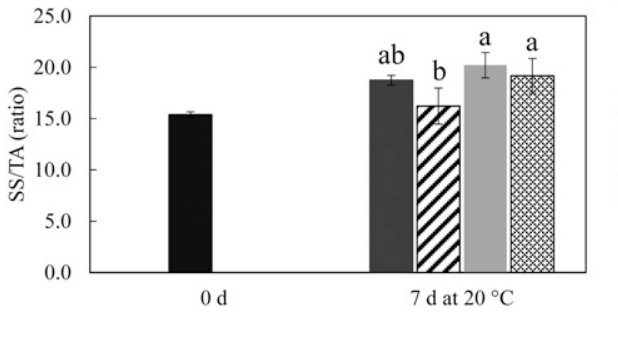

B 16.0

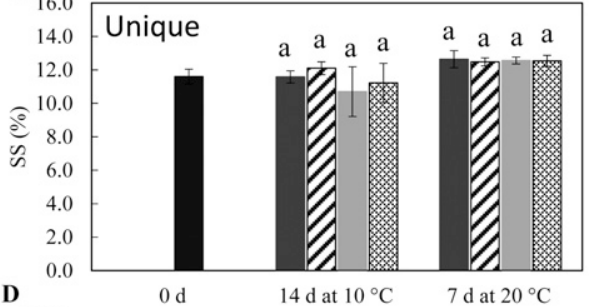

D
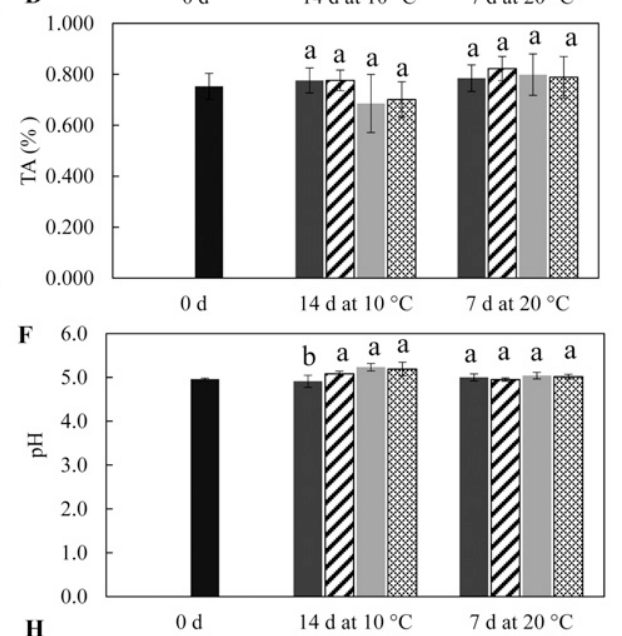

H

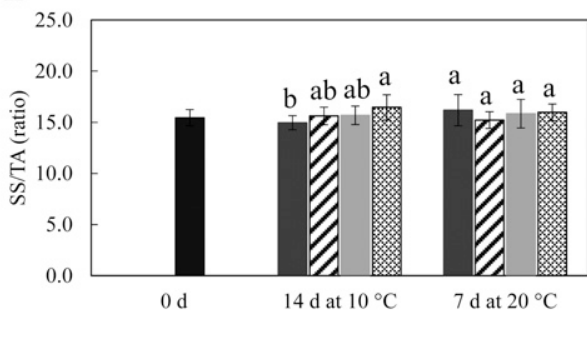

- Control $\square$ Shellac Nano $\quad$ Micro

Fig. 2. Nanoemulsions and microemulsions of carnauba wax compared with a commercial shellac microemulsion to determine effects on citrus fruit sugar and acid measurements. (A, B) Soluble solids (SS), (C, D) titratable acidity (TA), (E, F) pH, and ( $\mathbf{G}, \mathbf{H})$ SS/TA ratio values for 'Nova' mandarin and Unique' tangors, respectively, that were uncoated and coated with different coatings (five composite replicates of three fruit each). Columns with different letters are significantly different within each storage period according to Duncan's test $(P<0.05)$.

tangors, panelists were also instructed to squeeze fruit between the middle finger and thumb to rate firmness/hardness of the fruit using a 10 -point scale ( 0 soft to 10 hard). During both tests, each fruit was presented with a three-digit randomized code on a tray under daylight illumination.

Sensory Flavor Evaluation. 'Unique' fruit were juiced as described previously and frozen at $20{ }^{\circ} \mathrm{C}$. On the day of the panel, the juice was thawed overnight at $5{ }^{\circ} \mathrm{C}$, and $40 \mathrm{~mL}$ of juice was poured in 120-mL cups with lids (Solo, Urbana, IL). Coded juice samples were presented to panelists at $14 \pm 1{ }^{\circ} \mathrm{C}$, following the William's design. An additional cup of control juice was presented and labeled as "warm up." Panelists were instructed to first taste the "warm up" sample to familiarize their taste buds with the juice (O'Mahony et al., 1988). Then, they were instructed to take a sip from each coded cup and rank the samples for overall flavor from best to worst. They were allowed to taste as many times as necessary. Finally, a question was asked about any off-flavor perceived in each sample. Panelists were asked to rate off-flavor from 1 (no off-flavor) to 10 (extreme off-flavor) and to describe the off-flavor if perceived. Tasting was performed in isolated booths under red lighting. Data were recorded using Compusense Cloud (Compusense, Guelph, ON, Canada). Twenty-four panelists participated in a flavor evaluation of 'Unique' juice.

Statistical analyses. Physical and chemical parameters were analyzed using a univariate parametric analysis of variance (ANOVA) at each storage time, a multiple comparison Duncan test or GamesHowell (according to homogeneity of variance assumed or not), and a $t$ test for paired samples. The significance level for all analyzes was 5\%. IBM SPSS Statistics (subscription trial free version; IBM Corp., Armonk, NY) and R (R Core Team, Vienna, Austria) software were used. Ranked sensory data were analyzed using a critical absolute rank sum differences table at $P<0.05$ (Newell and MacFarlane, 1987). Tetrad test (Ennis, 2012) data were analyzed using an approximation equation for tetrad (Z-test) at $P=$ 0.05 . A comparison of sensory firmness scores was performed using a nonparametric ANOVA and multiple comparison of Kruskal-Wallis because of the ordinal level of the variables and four independent samples in the experiment $(P<0.05)$. Off-flavor ratings were analyzed by the ANOVA in a mixed model with random panelists using a statistical package (Senpaq version 5.01; Qi Statistics, Reading, UK). Principal component analysis (PCA) was performed using a multivariate statistical package (JMP version 13; SAS Institute, Cary, NC) to test the separation among coating treatments and storage times based on the volatile compounds.

\section{Results and Discussion}

Weight Loss. A major function of coatings on fruit is to retard water loss, which is measured as weight loss. Microemulsion (conventional) and nanoemulsion (experimental) carnauba wax coatings resulted in less weight loss compared with control and shellac-coated fruit, which were not different from each other, during the first experiment with 'Nova' mandarins (Fig. 1A). The microemulsion fared slightly better than the nanoemulsion for retarding weight (water) loss; therefore, perhaps, the more numerous and smaller lipid micelles were more permeable to water vapor than the larger lipid micelles of the microemulsion. For the second experiment with 'Unique' tangors, fruit weight loss was minimal after $14 \mathrm{~d}$ at $10{ }^{\circ} \mathrm{C}$ (less than $2 \%$ ) (Fig. 1B), with the control showing the most weight loss, but it was not different from that of the 

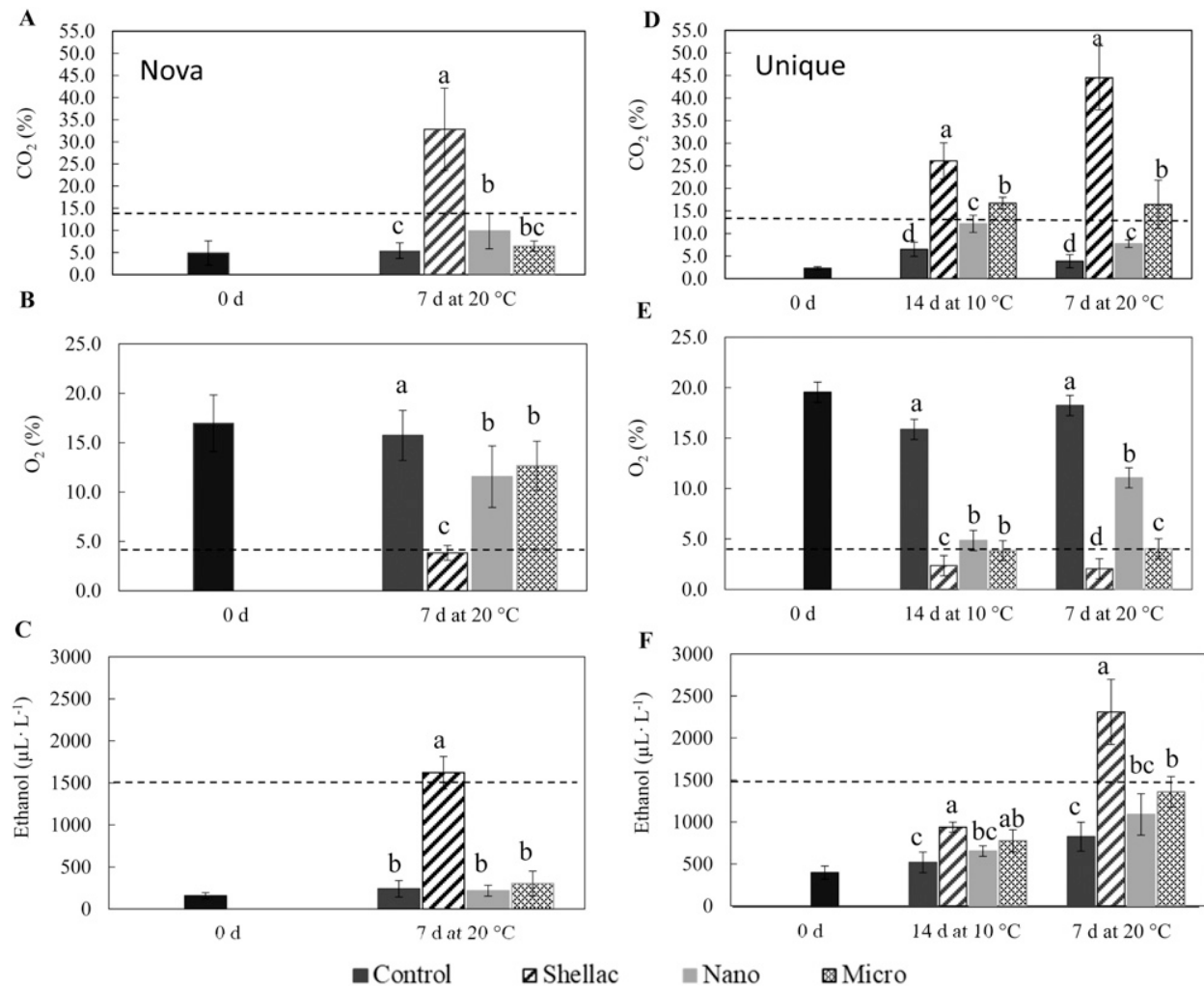

E
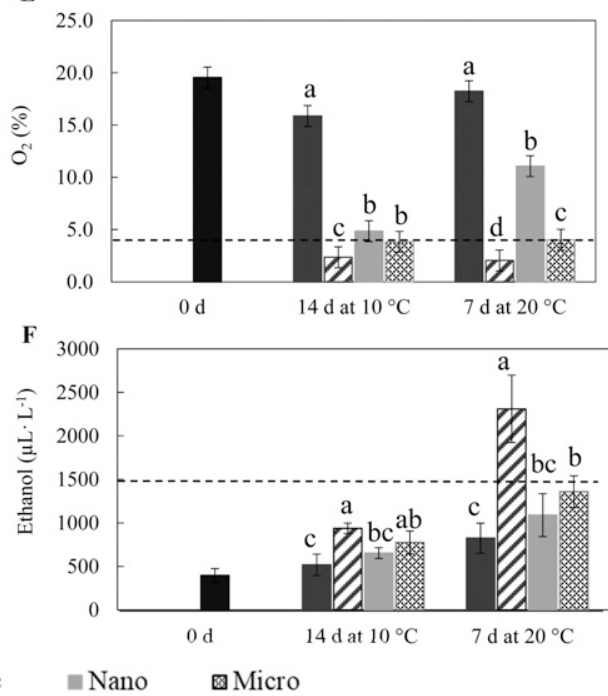

Fig. 3. Nanoemulsions and microemulsions of carnauba wax compared with a commercial shellac microemulsion to determine citrus fruit internal atmosphere modifications in $(\mathbf{A}, \mathbf{D})$ internal $\mathrm{CO}_{2}$ for 'Nova' mandarins and 'Unique' tangors, respectively, $(\mathbf{B}, \mathbf{E})$ internal $\mathrm{O}_{2}$ (10 fruit/treatment) for 'Nova' mandarins and 'Unique' tangors, respectively, and $(\mathbf{C}, \mathbf{F})$ juice ethanol values for 'Nova' mandarins and Unique' tangors, respectively (five replicates of three fruit each). Columns with different letters are significantly different for each storage period according to Duncan's test or the Games Howell test $(P<0.05)$. Dashed line represents the critical level according to Hagenmaier (2002) at which the mandarin flavor may be affected (internal $\mathrm{CO}_{2}$ and juice ethanol $>14 \%$ and $>1500 \mu \mathrm{L} \cdot \mathrm{L}^{-1}$, respectively, and $\mathrm{O}_{2}<4 \%$ ).

shellac. At the end of storage $\left(14 \mathrm{~d}\right.$ at $10^{\circ} \mathrm{C}+7 \mathrm{~d}$ at $\left.20^{\circ} \mathrm{C}\right)$, the microemulsion followed by the nanoemulsion coating exhibited less weight loss when compared with uncoated fruit, with the shellac coating being intermediate between control and the waxes.

Carnauba wax nanoemulsions and microemulsions are less permeable to water vapor than shellac due to its lipophilic nature. The solid lipid structure is dense and restricts water diffusion (Morillon et al., 2002); therefore, the results are not surprising. Several studies have reported that carnauba-based coatings decrease water loss (Jo et al., 2014; Kim et al., 2014).

SugARS AND ACIDS. Sweet and sour tastes, attributed to sugars and acids, are important to fruit flavor quality. There were minor statistical, but no practical, differences in the SS, TA, $\mathrm{pH}$, and ratio among treatments (Fig. 2). For 'Nova' mandarin coated fruit (Fig. 2A, C, E, and G), there were no differences in the SS between coatings (Fig. 2A); however, shellac had the highest TA and lowest $\mathrm{pH}$ (not different from the microemulsion), which resulted in the lowest SS/TA (not different from control) (Fig. 2C, E, and G). Generally, although not tested statistically, there was a slight increase in the $\mathrm{SS}, \mathrm{pH}$, and SS/TA and a decrease in the TA (except shellac for TA and $\mathrm{pH}$ and microemulsion for $\mathrm{pH}$ ) after $7 \mathrm{~d}$ at $20^{\circ} \mathrm{C}$. Similar results were reported by Obenland et al. (2011). The authors associated the higher SS/TA with the slightly superior flavor for mandarin fruit stored at $8{ }^{\circ} \mathrm{C}$ for up to 6 weeks and 1 week at $20^{\circ} \mathrm{C}$.
For 'Unique' tangors, there were also no substantial differences in the $\mathrm{SS}, \mathrm{TA}, \mathrm{pH}$, or ratio among treatments (Fig. 2B, D, F, and H). However, the $\mathrm{pH}$ and $\mathrm{SS} / \mathrm{TA}$ ratio for uncoated fruit were statistically the lowest among the treatments after $14 \mathrm{~d}$ at $10^{\circ} \mathrm{C}$ (not different from shellac or nanoemulsion for SS/TA) (Fig. 2F and $\mathrm{H}$, respectively), and there were no differences after an additional $7 \mathrm{~d}$ at $20^{\circ} \mathrm{C}$. Similarly, no significant differences in SS or TA were detected for different storage temperatures or during the storage period for 'Valencia' oranges coated with shellac, a cellulosebased coating, or uncoated fruit (Baldwin et al., 1995b).

INTERNAL GaSES. Fruit coatings can result in a modified fruit internal atmosphere that can affect flavor. The volatile ethanol is discussed here because it is affected by $\mathrm{O}_{2}$ levels and is an indicator of anaerobic respiration and the resulting off-flavor. For fruit in these two experiments, internal $\mathrm{CO}_{2}$ and juice ethanol generally increased and internal $\mathrm{O}_{2}$ decreased during storage (Fig. 3). For 'Nova' mandarins, the highest levels of $\mathrm{CO}_{2}$ and ethanol and the lowest $\mathrm{O}_{2}$ level were found with the shellac treatment, suggesting anaerobic respiration. The lowest levels of $\mathrm{CO}_{2}$ and ethanol and the highest $\mathrm{O}_{2}$ level were found in uncoated control fruit. The nano- and microemulsion carnauba wax coatings were intermediate and not different from each other (Fig. 3A-C). High ethanol has been directly linked to off-flavor and altered flavor (Baldwin et al., 1995b; Hagenmaier, 2000, 2002; Hagenmaier and Goodner, 2002; Ke and Kader, 1990). Hagenmaier (2002) coated several mandarin hybrids (eight cultivars) with wax (polyethylene and candelilla) and resin (shellac) and reported that a sensory taste panel found that fruit coated with the low gas permeability coating (shellac) had less fresh flavor compared with those coated with higher gas permeability coatings (polyethylene and candelilla waxes). The author demonstrated that the mandarin flavor may be affected when the internal $\mathrm{CO}_{2}$ is higher than $14 \%$, the internal $\mathrm{O}_{2}$ is lower than $4 \%$, and the juice ethanol content is higher than $1500 \mu \mathrm{L} \cdot \mathrm{L}^{-1}$ after $7 \mathrm{~d}$ storage at $20^{\circ} \mathrm{C}$ (see dashed lines in Fig. 3A-F).

'Unique' tangors showed the same trend as 'Nova' mandarins: fruit coated with shellac showed the lowest $\mathrm{O}_{2}$ along with highest $\mathrm{CO}_{2}$ and ethanol levels, followed by the carnauba microemulsion and nanoemulsion (Fig. 3D-F), especially after $7 \mathrm{~d}$ at $20^{\circ} \mathrm{C}$. Uncoated fruit had the lowest ethanol and $\mathrm{CO}_{2}$ levels, along with the highest $\mathrm{O}_{2}$ level. There were no differences between the nanoemulsion and control for ethanol levels or between the nanoemulsion and the microemulsion for $\mathrm{O}_{2}$ or ethanol after $14 \mathrm{~d}$ of cold storage and after the simulated marketing conditions for ethanol. Lower ethanol levels in the 
A
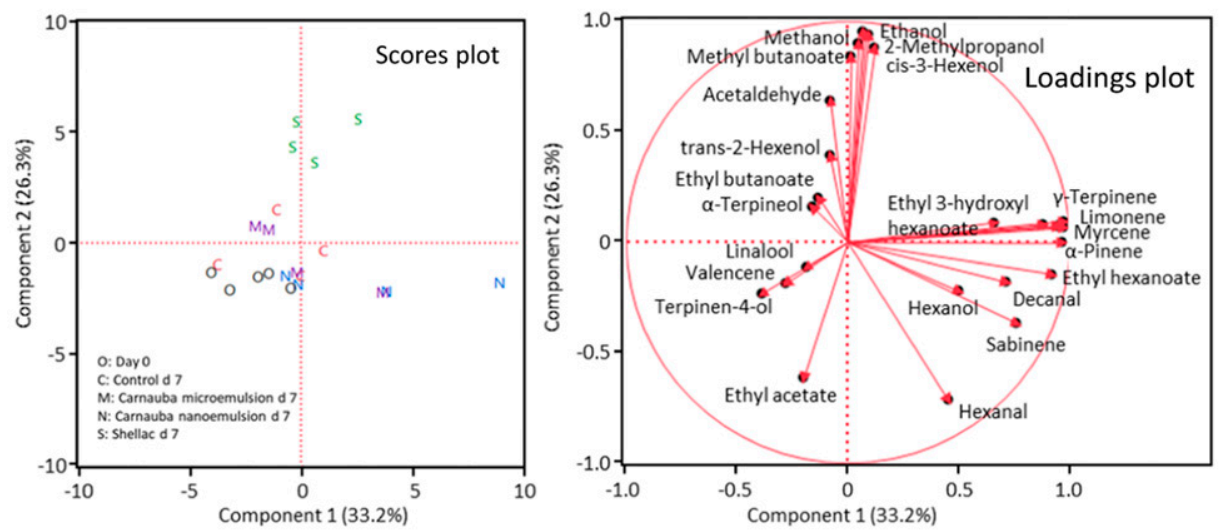

B
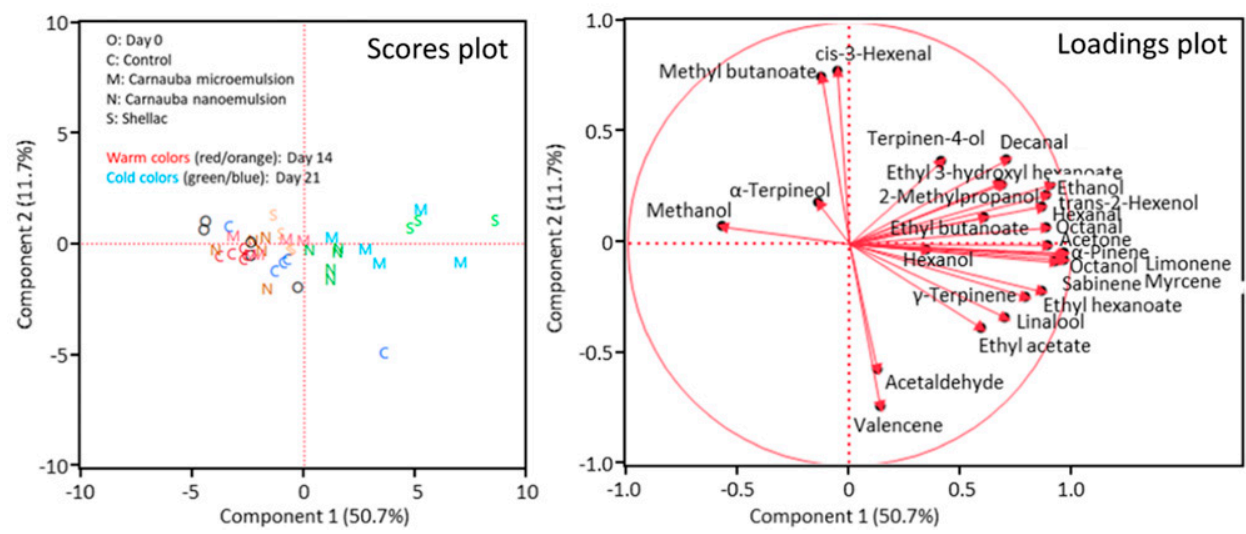

Fig. 4. Effects of shellac and carnauba coatings on citrus fruit aroma volatiles. Principle component analysis of 26 aroma volatile compounds measured in the juice of 15 citrus fruit (five composite replicates of three fruit each) for untreated fruit [control (C)] or fruit coated with three different coatings and stored at $20{ }^{\circ} \mathrm{C}$ [day 0 (O)]. (A) 'Nova' mandarins stored for $7 \mathrm{~d}$ at $20^{\circ} \mathrm{C}[\mathrm{C}$, shellac (S), nanoemulsion (N), and microemulsion (M)] and (B) 'Unique' tangors stored for $14 \mathrm{~d}$ at $10^{\circ} \mathrm{C}\left(\mathrm{red} /\right.$ orange $\mathrm{C}, \mathrm{S}, \mathrm{N}$, and $\mathrm{M}$ ) or for $14 \mathrm{~d}$ at $10^{\circ} \mathrm{C}$ plus $7 \mathrm{~d}$ at $20^{\circ} \mathrm{C}$ (green/ blue $\mathrm{C}, \mathrm{S}, \mathrm{N}$, and $\mathrm{M}$ ).

nanoemulsion coating could indicate better flavor, similar to that of uncoated fruit. Therefore, both carnauba coatings in this study were shown to be suitable for mandarins and tangors. Similar results were reported by Navarro et al. (2007) for 'Valencia' oranges and 'Marisol' tangerines. These authors reported that internal $\mathrm{CO}_{2}$ and ethanol were highest for fruit coated with shellac.

Shellac coatings can reduce gas exchange, thus modifying the internal atmosphere and creating an anaerobic/fermentative environment (Baldwin et al., 1995a; Hagenmaier, 2000; Hagenmaier and Baker, 1994). Usually resin coatings have low oxygen permeability properties, and shellac and wood resin are generally less permeable than waxes such as polyethylene, candelilla (Hagenmaier, 2002), and carnauba (Assis et al., 2008; Lin and Zhao, 2007). Therefore, lipid-based coatings, such as carnauba wax, present a more effective moisture barrier and are relatively permeable to gases (Assis et al., 2008; Lin and Zhao, 2007), resulting in less off-flavor.

Low oxygen atmospheres have been shown to result in an increased production of ethanol, methanol, and acetaldehyde in citrus fruit (Baldwin et al., 1995b; Davis, 1970; Shaw et al., 1990). To summarize this study, carnauba wax emulsions exhibited intermediate modifications of the fruit internal atmosphere of uncoated controls and shellac, presented a better moisture barrier than shellac, and resulted in less ethanol, with the nanoemulsion ethanol levels not different from those of uncoated fruit (Fig. 3C and F).

Aroma volatile analysis. The PCA plots of aroma volatiles of 'Nova' mandarins and 'Unique' tangors are shown in Fig. 4A and B, respectively. The PCA for 'Nova' mandarins (Fig. 4A) explained $59.5 \%$ of the data variation $(33.2 \%$ and $26.3 \%$ for components 1 and 2 , respectively) and $62.4 \%$ of the variation (mostly in component 1 ) for 'Unique' tangors (Fig. 4B), offering more evidence of the altered internal atmosphere due to coatings. For 'Nova' mandarins, shellac coatings were associated with ethanol, methanol, and acetaldehyde, indicating fermentation and other volatiles. The carnauba wax emulsions were clustered with control and 0-d samples or further down and to the right on component 1 , especially one nanoemulsion outlier, that was associated with common citrus terpenes, esters, and an aldehyde (limonene, myrcene, $\alpha$-pinene, $\gamma$-terpinene, ethyl hexanoate, and decanal among others) (Fig. 4A). For 'Unique' tangors, there were not many volatile differences after $14 \mathrm{~d}$ at $10{ }^{\circ} \mathrm{C}$ for any of the treatments, which were similar to those of $0-d$ juice, because the metabolism at this temperature is relatively slow (Fig. 4B). However, after cold storage followed by the simulated marketing period at $20{ }^{\circ} \mathrm{C}$, there were more differences between treatments. The aroma volatiles in the juice from $0-d$ fruit, controls, and the carnauba nanoemulsion treatment were associated with fewer volatiles (on the left side of component 1) but associated with methanol and $\alpha$-terpineol. The juice from fruit coated with the microemulsion and that from fruit coated with shellac were associated with more aroma volatiles on the right side of component 1 , including acetaldehyde, ethylacetate, ethanol, and acetone (Fig. 4), which are associated with anaerobic respiration. One control outlier was also associated with acetaldehyde as well as valencene. Although the other volatiles shown in Fig. 4 are mostly desirable and comprise the citrus aroma, the coatings may have trapped them and/or affected their synthesis, resulting in an altered flavor profile (as evidenced for 0 -d and control uncoated fruit juice) and possible off-flavor.

Fruit flavor evaluation. During the second experiment with 'Unique' tangors, the juice used to measure the aroma volatiles was also evaluated by a sensory panel for flavor (Fig. $5 \mathrm{~A}-\mathrm{C}$ ). After $14 \mathrm{~d}$ of cold storage, control fruit juice was ranked 
A

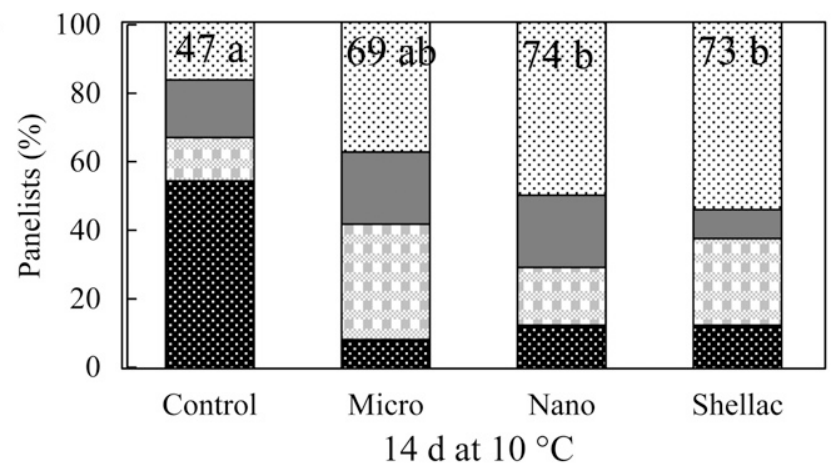

B

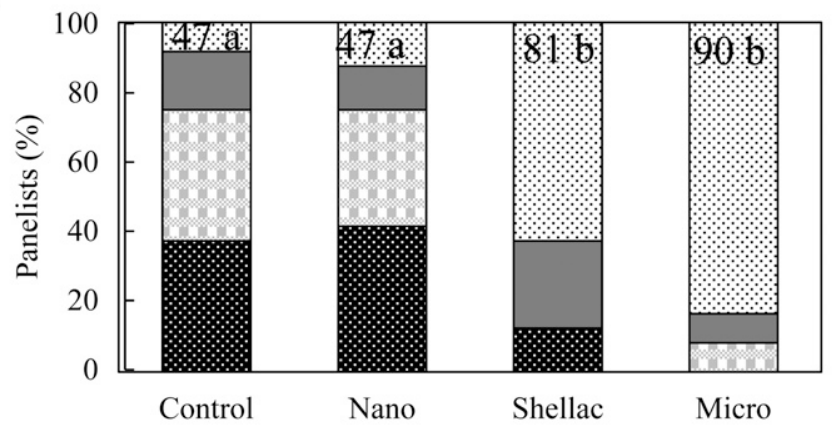

orank 1 (best flavor) $\square$ rank $2 \square$ rank 3 rank 4 (worst) $14 \mathrm{~d}$ at $10^{\circ} \mathrm{C} / 7 \mathrm{~d}$ at $20^{\circ} \mathrm{C}$

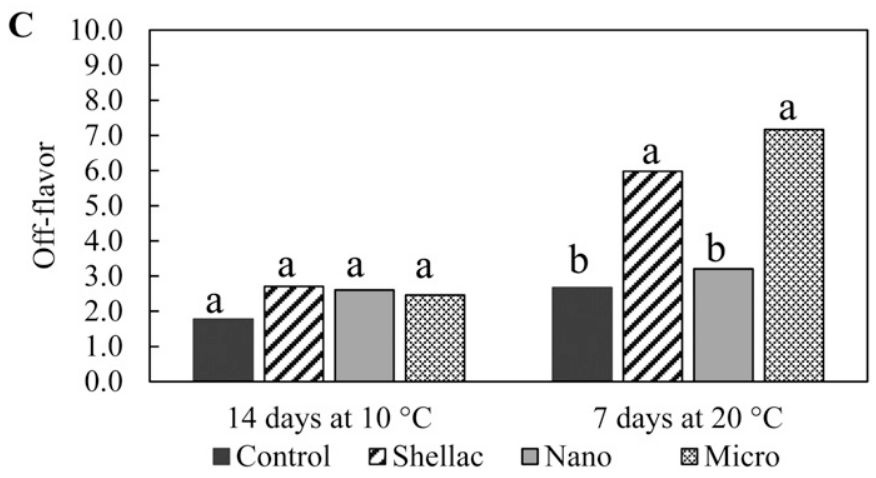

Fig. 5. Nanoemulsions and microemulsions of carnauba wax compared with a commercial shellac microemulsion for effects on citrus fruit juice flavor. Fruit juice was ranked for the tangerine flavor of 'Unique' tangors after $14 \mathrm{~d}$ at $10{ }^{\circ} \mathrm{C}$ (A) and after an additional $7 \mathrm{~d}$ at $20^{\circ} \mathrm{C}$ (B). Columns with different letters are significantly different according to the critical absolute rank sum differences table (value on figure bars, shown in order of ranking) at $P<0.05$ (data shown in order of ranking) (Newell and MacFarlane, 1987) for the four samples as determined by 24 panelists. Color shading depicts the percentage of panelists' selections. (C) Juice rated for off-flavor using a scale of 1 to 10 , where $1=$ none and $10=$ extreme. Numbers (mean rating, $n=24$ ) followed with the same letter are not statistically different according to Fisher's least significant difference test $(P<0.05)$.

as having the best mandarin flavor (lowest value), although it was not different from that of the carnauba microemulsion; however, the carnauba nanoemulsion and shellac-coated fruit were ranked as having the worst mandarin flavor (highest value), although it was not different from that of the carnauba microemulsion (Fig. 5A). For off-flavor at 14 d, there were no differences between treatments (Fig. 5C). This reflects the volatile data that showed few differences between treatments after cold storage (Fig. 4). After $14 \mathrm{~d}$ of cold storage followed
A

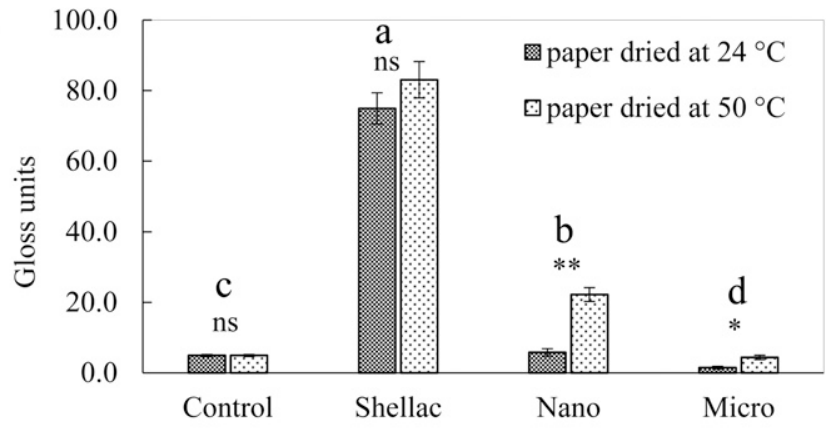

B

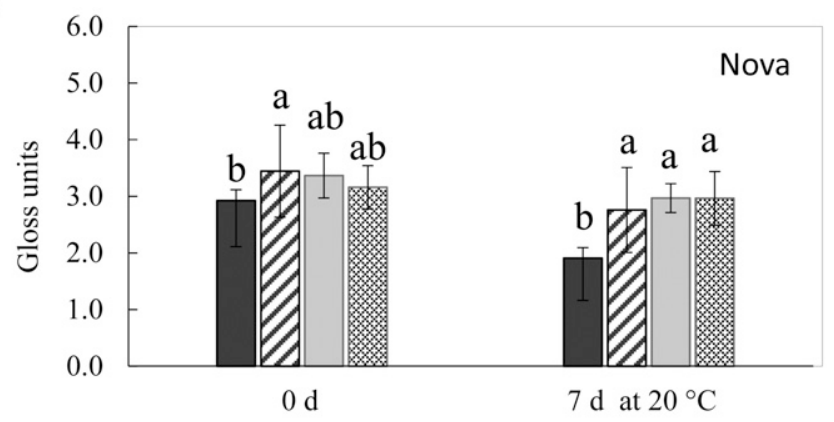

C

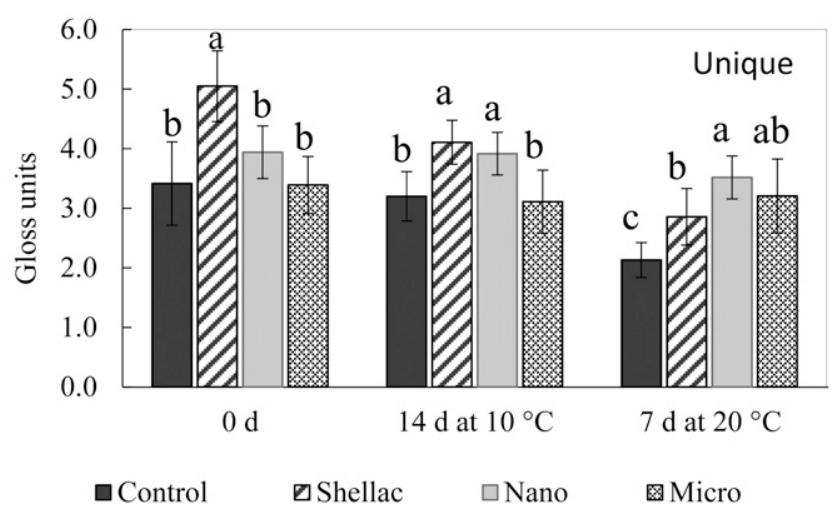

Fig. 6. Nanoemulsions and microemulsions of carnauba wax that impart shine measured as gloss units by a gloss meter. (A) Gloss units for uncoated (control) and coated black paper (five test papers with five measurements each). Differences were determined by the $t$ test $(* P<0.05, * * P<0.1)$. (B) Gloss units for uncoated (control) and coated 'Nova' mandarins $(\mathbf{C})$ and for 'Unique' tangors (10 fruit/treatment with two measurements/fruit). Coatings: shellac (shellac microemulsion), nano (carnauba nanoemulsion), and micro (carnauba microemulsion). For each storage period, columns with different letters are significantly different according to Duncan's test or the Games Howell test at $P<0.05$.

by $7 \mathrm{~d}$ at $20^{\circ} \mathrm{C}$, control fruit juice and the carnauba nanoemulsion-coated fruit juice were ranked highest for mandarin flavor, and the shellac-coated and microemulsion-coated fruit juices were ranked the lowest (Fig. 5B). This also reflects the increased volatile changes after the simulated marketing period at $20^{\circ} \mathrm{C}$ (Fig. 4). Similarly, regarding off-flavor, the control and carnauba nanoemulsion-treated fruit juices were rated lowest for off-flavor, and the shellac-treated and microemulsion-treated fruit juices were rated highest (Fig. 5C). This is consistent with the ethanol and other volatile levels, especially for shellac. The $\mathrm{CO}_{2}, \mathrm{O}_{2}$, and ethanol levels for the carnauba microemulsion were at or near levels that would predict flavor 


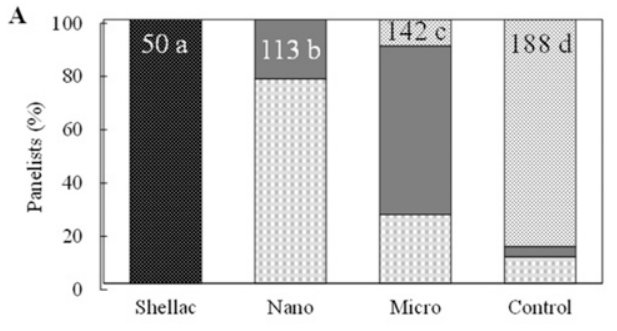

mrank 1 (most shine) घrank 2 घrank 3 घrank 4 (least shine) Nova $7 \mathrm{~d}$ at $20^{\circ} \mathrm{C}$
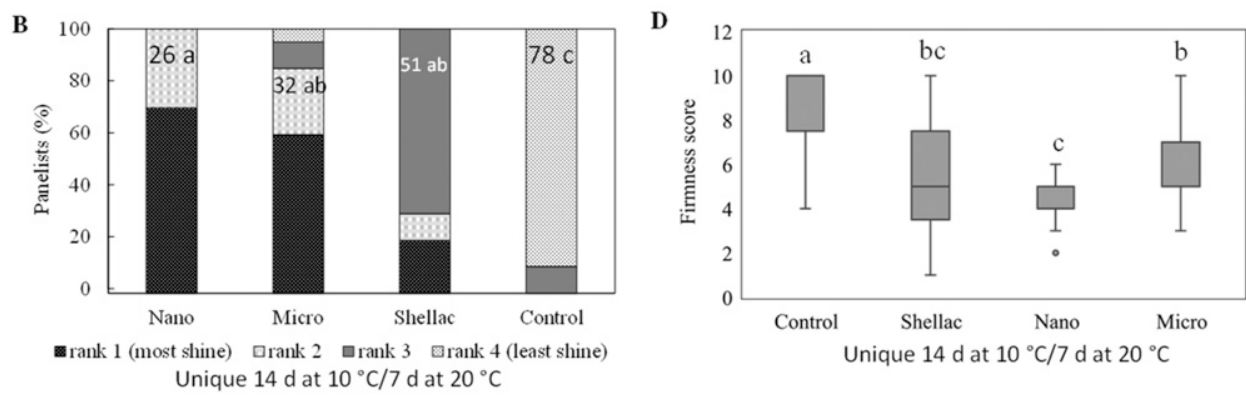

Fig. 7. Nanoemulsions and microemulsions of carnauba wax that impart visual shine to citrus fruit. Sensory shine ranking for 'Nova' mandarins stored for $7 \mathrm{~d}$ at $20^{\circ} \mathrm{C}(\mathbf{A})$ and 'Unique' tangors stored for $10 \mathrm{~d}$ at $10^{\circ} \mathrm{C}$ and then for $7 \mathrm{~d}$ at $20{ }^{\circ} \mathrm{C}(\mathbf{B})$ at end of the storage period. Columns with different letters were significantly different according to the critical absolute rank sum differences table at $P<0.05$ (value on figure bars, shown in order of ranking) (Newell and MacFarlane, 1987). Color shading depicts the percentage of panelists' selections. (C) Sensory tetrad test for 'Nova' mandarins at the end of the storage period. Columns with different letters were significantly different according to the approximation equation for tetrad (Z-test) at $P \leq 0.05$. (D) Sensory firmness perception for 'Unique' tangerine using a 10-point scale ( 0 soft to 10 hard) at the end of the storage period. Columns with different letters are different according to the Kruskal-Wallis multiple comparisons test $(P<0.05)$.

problems, but it is surprising that there were no flavor differences compared to shellac-coated fruit, which induced a much more extreme modification of the atmosphere than did the carnauba microemulsion, resulting in higher ethanol. Off-flavor descriptors for the shellac-coated and microemulsion-coated fruit were "rancid, "fermented," "chemical," "rotten fruit," and "soapy," which might be explained by higher amounts of ethyl acetate, ethyl hexanoate, ethyl-3-hydroxy hexanoate, and some aldehydes (Plotto et al., 2008).

Gloss analyses. Fruit visual shine boosts sales; therefore, coatings that impart shine are sought after by the coating industry, especially for citrus. During preliminary tests with paper sheets, gloss units on coated paper sheets increased when hot air was used to dry the coating surface and were generally higher when coatings were dried at $50{ }^{\circ} \mathrm{C}$ compared to $20^{\circ} \mathrm{C}$ (Fig. 6A), which is significant for the two carnauba emulsions. This indicates that the application of heated air helps coatings to dry and tends to impart more visual shine to the fruit. In fact, heated air-drying tunnels are often used for citrus by the industry (Hall, 2012). Shellac, as expected, had the highest gloss, which was significantly different from that of carnauba wax nanoemulsions and microemulsions and the uncoated paper (Fig. 6A).

For gloss on 'Nova' mandarin fruit (Fig. 6B), the shellac coating showed higher gloss units than the uncoated control initially; the gloss units of the carnauba wax coatings were not different from those of the shellac coatings or control. However, after $7 \mathrm{~d}$ of storage, all coatings showed more gloss units than the control, and there were no differences among coating treatments. For 'Unique' tangors (Fig. 6C), initially, the shellac showed the highest gloss units, which were significantly different from those of the other treatments, which were not different from each other. After $14 \mathrm{~d}$ of storage at $10^{\circ} \mathrm{C}$, shellac and the carnauba wax nanoemulsions showed the highest gloss units, with no difference between them, and there was no difference between the gloss units of the carnauba microemulsion and control. However, after $7 \mathrm{~d}$ at $20{ }^{\circ} \mathrm{C}$, the nanoemulsion showed the highest gloss units; the gloss units of the microemulsion were not different from those of the nanoemulsion or shellac. Citrus fruit loss of gloss units was observed for all treatments over time in storage; however, this loss was greater for shellac-coated fruit.

Similar results were reported by Navarro et al. (2007) for 'Valencia' sweet oranges and 'Marisol' tangerines treated with different coatings; the fruit gloss was highest with the shellac coating. In another study, after storage, the shellac gloss/shine decreased but was still shinier than that of the uncoated fruit. For that study, the shellac coating provided fruit with more shine and exhibited better weight loss control when compared with commercial cellulose-based coatings (Baldwin et al., 1995b).

SENSORY VISUAL SHINE ANALYSES. For 'Nova' mandarins, shellac-coated fruit were ranked highest for visual shine by panelists after $7 \mathrm{~d}$ at $20{ }^{\circ} \mathrm{C}$, followed by carnauba nanoemulsion, carnauba microemulsion, and the uncoated control (Fig. 7A). For 'Unique' tangors, the carnauba nanoemulsion had the highest visual shine score, although it was not different from that of the microemulsion; however, its shine score was higher than that of the shellac, and all shine scores were higher than that of the uncoated fruit (Fig. 7B) after $14 \mathrm{~d}$ at $10^{\circ} \mathrm{C}$ and 7 $\mathrm{d}$ at $20{ }^{\circ} \mathrm{C}$. There was no difference in the visual shine with the carnauba microemulsion and shellac. During the sensory pairing test (tetrad) with 'Nova' mandarins, the panelists recognized shellac-coated and uncoated fruit but could not differentiate between carnauba wax microemulsions and nanoemulsions based on the appearance of coated fruit (Fig. 7C).

The results for ranking based on visual shine are in agreement with those of Navarro et al. (2007), who reported that shellac-coated fruit ranked third for appearance (out of five treatments) and was considered too shiny. At the end of the cold storage $\left(14 \mathrm{~d}\right.$ at $\left.10{ }^{\circ} \mathrm{C}\right)$ and simulated marketing conditions $(7 \mathrm{~d}$ at $20^{\circ} \mathrm{C}$ ), uncoated tangors were more firm (hard, dried out). Those coated with the microemulsion and the nanoemulsion were the softest. Those coated with shellac were not different from those coated with either of the carnauba emulsions (Fig. 5D).

In conclusion, carnauba wax emulsion coatings allowed more gas exchange, resulting in fewer fruit internal atmosphere modifications, more sustainable shine (as measured by gloss 
units), and reduced water loss more effectively than a commercial shellac microemulsion on citrus fruit. Carnauba coatings did not affect the fruit sugar and acid levels, whereas shellac effects were minimal. The shellac coating induced the lowest $\mathrm{O}_{2}$ and highest $\mathrm{CO}_{2}$ and ethanol levels in fruit, which indicated anaerobic respiration and could predict undesirable flavor changes, as confirmed by a sensory panel. The panel found that the uncoated controls and the nanoemulsion-coated fruit had the most tangerine flavor and least off-flavor. An aroma volatile analysis showed that the shellac and microemulsion resulted in increased volatile levels, indicating alterations of the normal volatile profile. When the two carnauba coatings were compared, the microemulsion showed slightly better water loss control and the nanoemulsion generally exhibited higher gloss/shine, fewer modifications of the fruit internal atmosphere, fewer alterations of the aroma volatile profile, and lower ethanol levels. This resulted in better flavor quality for nanoemulsion-coated fruit juice, which was not different from the uncoated control fruit juice, which represented unaltered flavor. The effect on flavor is important because the use of coatings often detrimentally affects flavor, which affects repeat sales (Baldwin et al., 2014). For the carnauba emulsions, the materials used to make both emulsions are very similar, but the equipment is different. The nanoemulsion needs a closed reactor and a high-pressure homogenizer, which is a financial investment for coating companies, but the cost of the material is the same. The preparation time is $\approx 3 \mathrm{~h}$ for the nanoemulsion but $\approx 30 \mathrm{~m}$ for the microemulsion. The use of edible coatings is an environmentally friendly technology that can reduce postharvest losses and maintain fruit quality when used appropriately, and the carnauba nanoemulsion is as good as or better than the carnauba microemulsion for shine and flavor. Future work should evaluate decay control for carnauba and shellac microemulsions compared with the carnauba nanoemulsion for citrus fruit with and without antimicrobial essential oils.

\section{Literature Cited}

Assis, O.B.G., M.D.M.M. Ribeiro, M.E. Atarassi, G.P.P. Lima, and M.D. Ferreira. 2008. Aplicação de ceras em frutas e hortaliças, p. 144. In: M.D. Ferreira (ed.). Colheita e beneficiamento de frutas e hortaliças. Embrapa Instrumentação Agropecuária, São Carlos, Brazil.

Bai, J., V. Alleyne, R.D. Hagenmaier, J.P. Mattheis, and E.A. Baldwin. 2003a. Formulation of zein coatings for apples (Malus domestica Borkh). Postharvest Biol. Technol. 28:259-268, doi: 10.1016/S09255214(02)00182-5.

Bai, J., R.D. Hagenmaier, and E.A. Baldwin. 2003b. Coating selection for 'Delicious' and other apples. Postharvest Biol. Technol. 28:381390, doi: 10.1016/S0925-5214(02)00201-6.

Bai, J. and A. Plotto. 2012. Coatings for fresh fruits and vegetables, p. 185-242. In: E.A. Baldwin, R. Hagenmaier, and J. Bai (eds.). Edible coatings and films to improve food quality. CRC Press, Boca Raton, FL. doi: 10.1201/b11082.

Baldwin, E.A., J. Bai, A. Plotto, and M.A. Ritenour. 2014. Citrus fruit quality assessment; producer and consumer perspectives. Stewart Postharvest Rev. 2:1-7.

Baldwin, E.A., J. Bai, A. Plotto, R. Cameron, G. Luzio, J. Narciso, J. Manthey, W. Widmer, and B.L. Ford. 2012. Effect of extraction method on quality of orange juice; hand-squeezed, commercial-fresh squeezed and processed. J. Sci. Food Agr. 92:2029-2042, doi: $10.1002 /$ jsfa.5587.

Baldwin, E.A., J.K. Burns, W. Kazokas, J.K. Brecht, R.D. Hagenmaier, R.J. Bender, and E. Pesis. 1999. Effect of two edible coatings with different permeability characteristics on mango (Mangifera indica L.) ripening during storage. Postharvest Biol. Technol. 17:215-226, doi: 10.1016/S0925-5214(99)00053-8.

Baldwin, E., M. Nisperos-Carriedo, and R. Baker. 1995a. Edible coatings for lightly processed fruits and vegetables. HortScience 30:35-38, doi: 10.21273/HORTSCI.30.1.35.

Baldwin, E.A., M. Nisperos-Carriedo, P.E. Shaw, and J.K. Burns. 1995b. Effect of coatings and prolonged storage conditions on fresh orange flavor volatiles, degrees Brix and ascorbic acid levels. J. Agr. Food Chem. 43:1321-1330, doi: 10.1021/jf00056a065.

Davis, P.L. 1970. Relation of ethanol content of citrus fruits to maturity and to storage conditions. Proc. Florida State Hort. Soc. 83:294-298.

De Freitas, C.A.S., P.H.M. De Sousa, D.J. Soares, J.Y.G. Da Silva, S. Rathinaraj, S. Benjamin, and M.I.F. Guedes. 2019. Carnauba wax uses in food-A review. Food Chem. 29:38-48, doi: 10.1016/ j.foodchem.2019.03.133.

El-Hadi, M.A., F.J. Zhang, F.F. Wu, C.H. Zhou, and J. Tao. 2013. Advances in fruit aroma volatile research. Molecules 18:8200-8229, doi: 10.3390/molecules 18078200 .

Ennis, J.M. 2012. Guiding the switch from triangle testing to tetrad testing. J. Sens. Stud. 27:223-231, doi: 10.1111/j.1745-459x.2012.00386.x.

Food and Agricultural Organization of the United Nations. 2020. Crops-Extent, causes and prevention. 20 Jan. 2020. <http:// www.fao.org/faostat/en/\#data/QC>.

González-Saucedo, A., L.L. Barrera-Necha, R.L. Ventura-Aguilar, Z.N. Correa-Pacheco, S. Bautista-Baños, and M. Hernandez-Lopez. 2019. Extension of the postharvest quality of bell pepper by applying nanostructured coatings of chitosan with Byrsonima crassifolia extract (L.). Kunth. Postharvest Biol. Technol. 149:74-82, doi: 10.1016/j.postharvestbio.2018.11.019.

Hagenmaier, R.D. and K. Goodner. 2002. Storage of 'Marsh' grapefruit and 'Valencia' oranges with different coatings. Proc. Florida State Hort. Soc. 115:303-308.

Hagenmaier, R.D. 2000. Evaluation of polyethylene-candelilla coating for 'Valencia' oranges. Postharvest Biol. Technol. 19:147-154, doi: 10.1016/S0925-5214(00)00087-9.

Hagenmaier, R.D. 2002. The flavor of mandarin hybrids with different coatings. Postharvest Biol. Technol. 24:79-87, doi: 10.1016/S09255214(01)00121-1.

Hagenmaier, R.D. and R.A. Baker. 1997. Edible coating from morpholine-free wax microemulsions. J. Agr. Food Chem. 45:349352, doi: 10.1021/jf9604551.

Hagenmaier, R.D. and R. Baker. 1994. Wax microemulsions and emulsions as citrus coatings. J. Agr. Food Chem. 42:899-902, doi: 10.1021/jf00040a012.

Hagenmaier, R.D. and P.E. Shaw. 1991. Permeability of shellac coatings to gases and water vapor. J. Agr. Food Chem. 39:825829, doi: 10.1021/jf00005a001.

Hall, D.J. 2012. Edible coatings from lipids, waxes and resins, p. 79101. In: E.A. Baldwin, R. Hagenmaier, and J. Bai (eds.). Edible coatings and films to improve food quality. CRC Press, Boca Raton, FL. doi: 10.1201/b11082.

Jo, W.-S., H. Song, N. Song, J. Lee, S.C. Min, and K.B. Song. 2014. Quality and microbial safety of 'Fuji' apples coated with carnaubashellac wax containing lemongrass oil. Lebensm. Wiss. Technol. 55:490-497, doi: 10.1016/j.lwt.2013.10.034.

Ke, D. and A.A. Kader. 1990. Tolerance of 'Valencia' oranges to controlled atmospheres determination by physiological responses and quality attributes. J. Amer. Soc. Hort. Sci. 115:770-783.

Kim, I.H., Y.A. Oh, H. Lee, K.B. Song, and S.C. Min. 2014. Grape berry coatings of lemongrass oil-incorporating nanoemulsion. Lebensm. Wiss. Technol. 58:1-10, doi: 10.101610/j.lwt.214.03.018.

Lin, D. and Y. Zhao. 2007. Innovations in the development and application of edible coatings for fresh and minimally processed fruits and vegetables. Compr. Rev. Food Sci. Food Saf. 6:60-75, doi: 10.1111/j.1541-4337.2007.00018.

Luangtana-Anan, M. and S. Limmatvapirat. 2019. Shellac-based coating polymer for agricultural applications, p. 487-524. In: T. 
Gutiérrez (ed.). Polymers for agri-food applications. Springer, New York, NY.

Miranda, M. 2015. Revestimento nanoestruturado de cera de carnaúba na manutenção da qualidade pós-colheita de tomates. MS Thesis, Federal University of São Carlos, São Carlos, Brazil. 14 Oct. 2020. $<$ https://repositorio.ufscar.br/bitstream/handle/ufscar/8588/ DissMM.pdf? sequence $=1 \&$ isAllowed $=\mathrm{y}>$.

Morillon, V., F. Debeaufort, G. Blond, M. Capelle, and A. Voilley. 2002. Factors affecting the moisture permeability of lipid-based edible films: A review. Crit. Rev. Food Sci. Nutr. 42:67-89, doi: 10.1080/10408690290825466.

Navarro, M.-L., M.B. Pérez-Gago, K. Goodner, and A. Plotto. 2007. New composite coating containing HPMC, beeswax, and shellac for 'Valencia' oranges and 'Marisol' tangerines. Proc. Florida State Hort. Soc. 120:228-234.

Nayak, S.L., S. Sethi, R.R. Shaarma, and U. Prajapati. 2019. Active edible coatings for fresh fruits and vegetables, p. 417-432. In: T.J. Gutiérrez (ed.). Polymers for agri-food applications. Springer, Cham, Switzerland. Newell, G.J. and J.D. MacFarlane. 1987. Expanded tables for multiple comparison procedures in the analysis of ranked data. J. Food Sci 52:1721-1725, doi: 10.1111/j.1365-2621.1987.tb05913.x.

Nguyen, N.H.V. and D.H. Nguyen. 2020. Effects of nano-chitosan and chitosan coating on the postharvest quality, polyphenol oxidase activity and malondialdehyde content of strawberry (Fragaria ×ananassa Duch.). J. Hort. Postharvest Res. 3:11-24, doi: 10.22077/JHPR.2019.2698.1082.

Nisperos-Carriedo, M., E. Baldwin, and P. Shaw. 1991. Development of an edible coating for extending postharvest life of selected fruits and vegetables. Proc. Florida State Hort. Soc. 104:122-125.

Nugent, V., K.E. Magnus, and C.V. Bent. 1967. The ortanique orange. Trop. Sci. 19:182-185.
Obenland, D.S., B. Collin, J. Mackey, J. Sievert, and M.L. Arpaia. 2011. Storage temperature and time influences sensory quality of mandarins by altering soluble solids, acidity and aroma volatile composition. Postharvest Biol. Technol. 59:187-193, doi: 10.1016/ j.postharvestbio.2010.09.011.

O'Mahony, M., U. Thieme, and L.R. Goldstein. 1988. The warm-up effect as a means of increasing the discriminabilty of sensory difference tests. J. Food Sci. 53:1848-1850, doi: 1.1111/j.13652621.1988.tb07858x.

Palou, L., S.A. Valencia-Chamorro, and M.B. Pérez-Gago. 2015. Antifungal edible coatings for fresh citrus fruit: A review. Coatings 5:962-986, doi: 10.3390/coatings5040962.

Pilon, L., P.C. Spricgo, M. Miranda, M.R. Moura, O.B.G. Assis, L.H.C. Mattoso, and M.D. Ferreira. 2014. Chitosan nanoparticle coatings reduce microbial growth on fresh-cut apples while not affecting quality attributes. Intl. J. Food Sci. Technol. 50:440-444, doi: 10.1111/ijfs.12616.

Plotto, A., C.A. Margaria, K.L. Goodner, and E.A. Baldwin. 2008. Odour and flavor thresholds for key aroma components in an orange juice matrix: Esters and miscellaneous compounds. Flavour Fragrance J. 23:398-406, doi: 1.1002/ffj.1470.

Shaw, P.E., R.D. Carter, M.G. Moshonas, and G. Sadler. 1990. Controlled atmosphere storage of oranges to enhance aqueous essence and essence oil. J. Food Sci. 55:1617-1619, doi: 10.1111/ j.1365-2621.1990.tb03584.x.

U.S. Department of Agriculture. 2020. Citrus: World markets and trade. 14 Oct. 2020. <https://apps.fas.usda.gov/psdonline/circulars/citrus.pdf >. Wang, L., E.A. Baldwin, Z. Yu, and J. Bai. 2015. The impact of kitchen and food service preparation practices on the volatile aroma profile in ripe tomatoes: Effects of refrigeration and blanching. HortScience 50:1358-1364, doi: 10.21273/HORTSCI.50.9.1358. 